\title{
Utilising the Linguistic Knowledge of the Speech Community
}

\section{Introduction}

Threatened language groups worldwide continue to experience language loss due to official language policies. While many indigenous and minoritised language communities face challenges as they advocate for their mother tongue, communities which have faced significant loss of intergenerational transfer of language in the home, also face even greater challenges.

To aid language revitalisation efforts, one tool being utilised by Māori in Aotearoa/New Zealand, and by other communities internationally, is immersion education. This research examines whether, and to what extent, members of the te reo Mãori (the Māori language) speech community are actively involved in the formal education classrooms of Kura Kaupapa Māori (Māori immersion schools) and Kura ā-iwi (Iwi (tribal) immersion schools). While the particular focus in this research is positioned around members of the native-speaking grandparent generation, it is also vital here to acknowledge the important role of the dedicated second language learner in the language revitalisation of Mãori.

Within this focus is the recognition that while the ultimate goal of language revitalisation is the self-sustaining intergenerational transfer of language within the home, this research will examine how schools can bridge the home/school nexus and can be catalysts for language use within the family and wider community.

For the purposes of this paper, topics are structured and presented in a linear format, one idea following the other, but, it is important to remember all topics interact and are cyclical, with each category potentially influenced by, and influencing, the other categories. 
This has been reflected in the design you now see in the design on the next page. The concentric cirlces represent the movement between, and the influence of, the macro on the micro level (global to local) and vice versa. A concept ever present in this topic. Additionally, all smaller circles, representing some of the elements of the wider project, are contained within a single larger circle, and all smaller circles are connected by concentric circles. This is to illustrate the need for holistic strategies and interconnected perspectives, crucial in language revitalisation strategies.

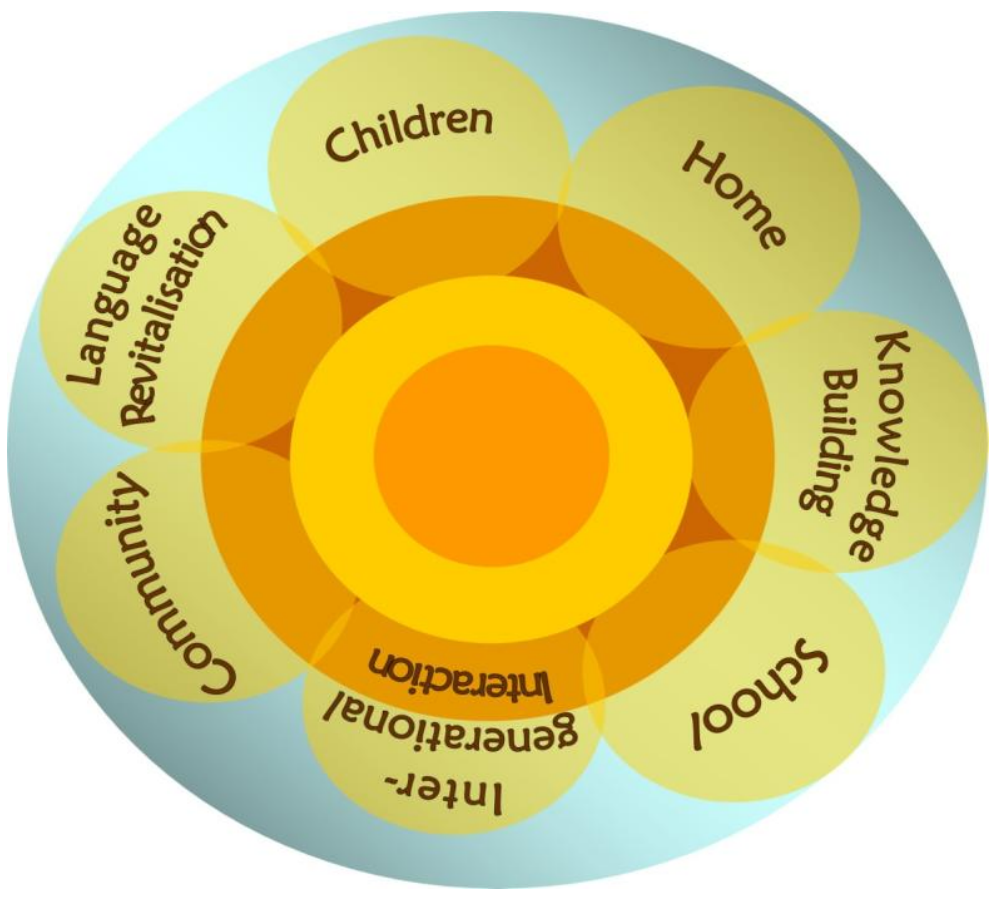

\section{Research Context}

At a global scale Indigenous and minoritised endangered language communities face many challenges as they advocate for their mother tongue. Previous assimilation and other subtractive-type language policies implemented by the governments in countries such as New Zealand, the United 
States, Great Britain, and elsewhere, have often resulted in a generational language gap within families. This gap, between those who do and do not speak the indigenous or minoritised language fluently, restricted the natural process of intergenerational language transmission within the home. Language communities, such as the Māori in New Zealand, who have significantly lost intergenerational transfer of language in the home now face even greater challenges as they fight to revitalise the use of their language.

In these communities the native speakers are often members of the grandparent generation. It is these native speakers who maintain the traditional linguistic knowledge of the language, as taught to them by the intergenerational transmission of the language from their elders. This ever aging native speaker population puts the threatened indigenous languages in a critical situation because as the native speaker population ages and passes, communities lose the knowledge of the language these speakers held.

The language of the native speaker is a repository of traditional ways of expression and idiosyncrasies of the language. This language, with grammatical structures that may sound unnatural to a second language learner, has the important ability to ensure that te reo Māori (the Māori language) remains te reo Māori, rather than, develop into Māori words with an English structure (Kāretu, 2002). The language of this elder generation is the language that illustrates uniqueness and beauty of the Māori language. Languages evolve naturally, but it's also important that this evolution should occur within the essence of the language, i.e., what makes it unique and, what connects it to the language of the past generations.

Within the realm of language usage, it is seen in the literature that while research exists pertaining to mother tongue medium education, and intergenerational language transfer in the home and wider community, few studies examine the overlap, or potential for overlap, that exists between language revitalisation efforts incorporating speech community members in formal schooling pedagogy. This observation is reinforced by Christensen (2001) who discusses the lack of status planning in New Zealand language revitalisation efforts to increase the actual use of te reo Māori across multiple domains, especially in conjunction with the home. 
According to Fishman (1991) and reinforced by many others $^{1}$, for a language to survive, the ultimate goal of language revitalisation is the self-sustaining intergenerational transfer of language within the home. But, as indicated previously, this method of linguistic transmission and survival is not widespread in New Zealand. There is a generational language gap, of significant proportion, between the older native speaker generation and the students in language immersion contexts.

This prompts the important issue of what efforts, if any, are being made within mother tongue language revitalisation programmes to utilise the language abilities of the older generations, within formal education pedagogy. Thus, not only promoting traditional intergenerational language learning among younger generations, but also as a means of bridging the home/school nexus serving as a catalysts for language use within the family and wider community.

\section{Purpose of the study}

Historically, the teaching and learning of all aspects of an Indigenous society were based on intergenerational learning with elders in the community. According to Hemara (2000) in Māori society, traditionally education was intergenerational with small student numbers and special importance placed on one-on-one interaction, with the kaumattua (family elders) taking on the role of teachers and guardians, and instructing the younger generations in holistic life-long learning. In the 1980s Kōhanga Reo and Kura Kaupapa Māori were established. More than just mother tongue medium education programmes, meant to aid the effort toward the revitalisation of te reo Mãori, these were established to incorporate tikanga Māori (Māori customs), te ao Māori (the Māori world), and mātauranga Māori (Māori knowledge) into the formal school setting.

Despite national and international support and advocacy for mother tongue medium education from organisations such as the United Nations, mother tongue medium education

The reference directly cites Fishman, 1991, but this work and the idea it supports regarding the ciritcal importance of language transmission in the home for a langauge to survive is reiterated throughout the literature on language revitalisation including King (2001), O Laoire (2006); Reedy (2000); Romaine (2007), Spolsky (1995) to name just a few. 
programmes are still in need of more qualified teaching staff and resources. So, despite considerable effort, many programmes continue to struggle for results.

In New Zealand, contemporary challenges faced by Kura Kaupapa Māori, and many other indigenous and minoritised medium education programmes globally, include limited instructional resources in the language of instruction, a need for more teachers with language fluency, and a need to bridge the divide between language use at school and in the home/community (Christensen, 2001; Doerr, 2009; Hinton, 2003; Ka‘ai, 1995; Ó Laoire, 2006; Reyhner, Lockhard, \& Rosenthal, 2000; Reedy et al., 2011).

These challenges present issues of not only quantity and availability, but more importantly quality: quality of language instruction and quality of instruction in the language. According to Christensen in his work Ko te Whare Whakamana: Mãori Language Revitalisation (2001):

The relatively large numbers of second language learners of Māori in comparison with native speakers has led to a further decline in the corpus of the language, evidenced in code simplification, aberrant grammatical structure, and dwindling use of idiom, colloquial expression and metaphor. (p. 58)

These challenges are exacerbated by the limited intergenerational language transfer taking place in the homes and communities and the aging native speaking generation. Ever present in the literature is the point that languages will not survive through language use in education alone alone (Christensen, 2001; Earle, 2007; Fishman, 1991; Karetu2 2002; Romaine, 2007). Function and status in the home, community, and wider society is needed to sustain a language, and progress revitalisation efforts.

According to the 2011 report Te Reo Mauriora, "Sustainability requires the merging of the current educational focus with a focus on growing the language in homes" (Reedy et al., 2011, p. 19). This dichotomy between the home/community and school is seen in a review of the current literature in language revitalisation. There appears to be a compartmentalisation between language usage in the home/community and language usage in school.

${ }^{2}$ Dr Tīmoti Kāretu's name is listed without the macron in his surname in the 2002 publication. 
A whânau presence in education is seen in the literature with regard to policy/decision making, and general interaction with the school (New Zealand Ministry of Education, 2008; New Zealand Ministry of Education, nd; Te Kura Māori, 2010), but there has been little to no documentation on whannau Māori language classroom interaction, and how actions from the classroom influence the wider language revitalisation efforts.

An examination of this overlap, or potential for overlap, and establishment of cross-populating measures to bridge this school/home/community divide is needed to aid language revitalisation efforts formed within the structure of formal education, to further their impact on the wider revitalisation of te reo Mãori.

\section{Methodolgy}

Narrative inquiry will provide the overall methodological approach for this research. This methodology is most often understood to be an ethnographic approach to eliciting understanding of themes, perceptions, time, and places (Pavlenko, 2002). It is situated by the theory that, "we as human beings make sense of random experience by the imposition of story structures" (Sinclair Bell, 2002, p. 207). Narrative inquiry allows for a holistic understanding of lived experiences (Trahar, 2009) through allowing exploration though a "three-dimensional narrative inquiry space" (Clandinin, 2006, p. 46). These ideas, of humans naturally living storied lives, is also present in Connelly and Clandinin's Stories of Experience and Narrative Inquiry in which the use of narrative inquiry in studies of educational experience is explored (1990).

Since being a teacher/educator is not a profession that ends at the classroom door, narrative inquiry will allow for exploration of the holistic experience of teachers, inside and outside of the classroom, as members of speech communities, and as members of a language revitalisation movement.

This research is not just a question of if there are, or are not, members of the speech community present in a classroom, it is about the space and place in which the education system and te reo Mãori language revitalisation movement finds itself, which lead to the research question being asked. 
This methodology allows for a freedom in which the researcher can engage with the participant through mutual stories. It also allows for flexibility. If a participant is going 'off topic' it is not 'bad' it is another aspect of the process through which elements contributing to a holistic understanding can be uncovered.

The use of inquiry probes allows for the exploration of memory, identity, and meaning at a variety of levels and over a period of time. A sample of two series of questions are below:

- Childhood Education:

What was education like for you growing up? What was education like at home? What was education like at school? Who was involved?

- Contemporary Education:

What involvement do you have with the kura today? What similarities and differences do you see in education from when you were growing up?

Additionally, as the researcher is neither Mãori, nor from New Zealand, a methodology was needed that would also be appropriate and applicable for research based in a Māori context. Referring to Bishop, Smith noted:

As a research tool... storytelling is a useful and culturally appropriate way of representing the 'diversities of truth' within which the story teller rather than the researcher retains control. (1999, p.145)

\section{Knowledge Building}

This research will further explore speech community members as assisting student learning as non-teacher roles in the classroom, not as formal teachers. The philosophy would be that of bringing native speakers into the classroom in nonteacher roles as knowledge building facilitators.

As with anything in the capacity of learning and teaching there are benefits and challenges of incorporating additional participants into the classroom. In recognition of this, the paper will now look at just some of the potential challenges, but more importantly the potential benefits of incorporating members of the speech community into the classroom. 


\section{Challenges}

- The number of native speakers remaining.

- The age of many in the native speaker population.

- Overcoming negative perceptions of education due to previous restrictions of te reoMāori in school, punishment for its usage, negative experiences in formal education.

- $\quad$ Overcoming negative language myths such as teaching children in another language will only confuse them, children who are bilingual will not be fully profiecient in either language.

- Resources inclucing but not limited to the native speaker's ability to travel to the school. The means to travel to the school. Or, the schools ability to provide ways and means for transportation if neccessary.

- Time to participate.

- Desire to participate.

- Motivation to participate.

- Awareness of not only a need, but that they can contribute to the formal schooling environment.

Now more importantly the potential benefits.

\section{Benefits}

- Interactive education in small groups - providing additional communicative interaction time with native speakers

- $\quad$ Building active language skills.

- Informal or formal interaction between the older and younger speakers.

- As a resource - providing an opportunity for more teaching activities

- Incorporation of language documentation resources which are often passive learning tools (videos, documnets, audio recording) into an active learning environment. An environment in which children can discuss and ask questions of an elder around these resources, utilsing a combination of active and passive language and learning skills.

- Teacher support, illustrating the nature that educating a child is a co-operative venture. 
- Motivation - spread their enthusiam and motivation to participate in language revitisation efforts and student language learning throughout the wider community.

- Awareness - raise awareness of the need for language revitalisation and usage within the wider community in multiple societal domains and the potential the community has to contribute to this process. Potentially helping to bridge the gap between school and home community usage.

\section{Potential Methods}

The incorporation, or re-incorporation, of wider speech community members into the classroom only serves to potentially strengthen the significant efforts of Māoriimmersion schools to aid in the revitalisation of te reo Māori and to provide a holistic, culturally-appropriate education for their students. Now, just a brief discussion of a what could be a few potential methods for incorporating the speech community in the the classroom.

Intergenerational learning in the classroom can incorporate the oral narrative traditions of the past into the predominately written literature bases of education. It can also help to provide daily interactive language, in addition to classroom language used with teachers to help facilitate language use outside the classroom and in the wider community. Additionally, if students feel comfortable engaging in te reo Mãori conversations with those other than teachers and students in the space of the classroom, this could also encourage the wider use of the language with the community members with whom they engaged in the classroom.

One exercise that could be tried, ties into the methodology to be utilised in this research. The school could invite native speaker speech community members into classrooms for small group or one-on-one discussions utilising pre-established prompts. The use of pre-established prompts distributed by the teacher will at first help the students and speech community members to engage the different generations in conversations, and will help both parties learn about the life experiences of the other. Students and community members could then also work together to develop their own questions 
to further enhance the linguistic and cultural exchange of lived experiences taking place.

This could also be expanded to include Radio or pod-casts for the children and community members to develop and engage in.

While formal education language revitalisation programmes can be a tool for re-establishing a threatened language in a community, taking language usage from the classroom to usage within the wider community must also be addressed for linguistic survival. In the end it is an individual decision to speak or not to speak te reo Māori according to Dr. Kāretu in a 2008 publication, but the current generations has the responsibility to give future generations the linguistic tools to make that decision on their own.

\section{Conclusion}

In conclusion I go back to my initial graphic illustrating that whether at a local or national scale that:

- Everything is connected.

- Everything is a tool toward the ultimate goal of the revitalisation of the language.

- And, the importance of the cycle of learning and teaching not only in the education but in our everyday lives within the wider community.

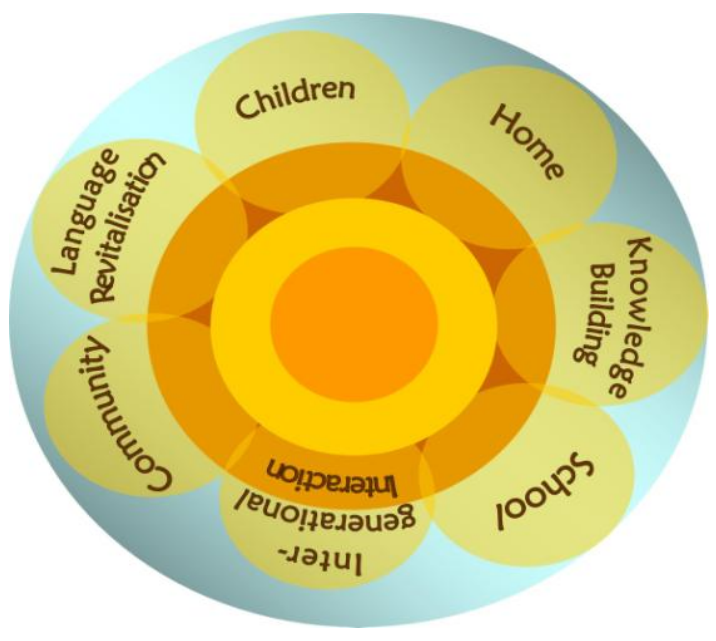

Te Kaharoa, vol. 5, Special Edition, 2012, ISSN 1178-6035 


\section{References}

Christensen, I. (2001). Ko te whare whakamana: Mãori Language Revitalisation. (Unpublished doctorial thesis). Massey University, Palmerston North, NZ.

Clandinin, D. J. (2006). Narrative inquiry: A methodology for studying lived experience. Research Studies in Music Education. 27, 44-54.

Connelly, F. M., \& Clandinin, D. J. (1990). Stories of experience and narrative inquiry. Educational Researcher. 19(5), 2-14.

Doerr, N.M. (2009). Meaningful inconsistencies: Bilingual nationhood, the free market, and schooling in Aotearoa/New Zealand. Oxford: Berghahn Books.

Earle, D. (2007). He tini manu reo: Learning te reo Māori through tertiary education. Wellington: New Zealand Ministry of Education.

Fishman, J. (1991). Reversing language shift. Clevedon: Multilingual Matters LTD.

Hemara, W. (2000). Mãori pedagogies: A view from the literature. Wellington: New Zealand Council for Educational Research/Te Rūnanga o Aotearoa mo te Rangahau I te Matauanga.

Hinton, L. (2003). How to teach when the teacher isn't fluent. In J. Rehyner, O. Trujillo, R.L. Carrasco \& L. Lockard (Eds.) Nurturing native languages. Flagstaff, AZ: Northern Arizona University.

Ka'ai, T. (1995). Te tātari i te kaupapa. (Unpublished doctorial thesis). The University of Waikato, Hamilton, NZ.

Karetu, T. (2002). Māori - New Zealand latin? In B. Burnaby \& J. Reyhner (Eds.) Indigenous languages across the community. Flagstaff: Northern Arizona University.

Kāretu, T. (2008). Te kete tuawhā, te kete aroiti - The fourth basket. Te Kaharoa. 1, 87-99.

King, K. A. (2001). Language revitalization: Processes and prospects. Clevedon: Multilingual Matters.

New Zealand Ministry of Education. (2008). Official version of te aho matua o ngā kura kaupapa Māori and an explanation in English. Supplement to New Zealand Gazette. (No. 32).

New Zealand Ministry of Education. (nd). Te Marautanga o Aotearoa reo Pākehā. Wellington: Ministry of Education.

Ó Laoire, M. (2006). Language education for language revival. In K. Brown (Ed.) Encyclopaedia of language and linguistics.Volume 6. Oxford: Elsevier Ltd.

Pavlenko, A. (2002). Narrative study: Whose story is it, anyway? TESOL Quarterly, 36(2), 213-218.

Reedy, T. (2000). Te reo Māori: The past 20 years and looking forward. Oceanic Linguistics. 39(1), 157-168.

Reedy, T., Bird, P., Maxwell, T.K., O’Regan, H., Dewes, C., Shortland, R., Papa, P., \& Waho, T. (2011). Te reo mauriora te arotakenga o te rāngai reo Māori me te rautaki reo Mãori - Review of the Mãori language sector and the Māori language strategy. Commissioned by Te Puni Kōkiri. Retrieved from http://www.tpk.govt.nz/en/consultation/ reviewmlss/report/. 
Reyhner, J., Lockhard, L., \& Rosenthal, J. (2000). Native American languages. In J. Rosenthal (Ed.) Handbook of undergraduate second language education. Mahwah, N.J.: L. Erlbaum Associates.

Romaine, S. (2007). Preserving endangered languages. Language and Linguistics Compass 1(1-2), 115-132.

Sinclair Bell, J. (2002). Narrative inquiry: More than just telling stories. TESOL Quarterly, 36(2), 207-213.

Smith, L. T. (1999). Decolonizing methodologies: Research and Indigenous Peoples. Dunedin: University of Otago Press.

Spolsky, B. (1995). Conditions for language revitalization: A comparison of the cases of Hebrew and Māori. Current Issues in Language and Society, 2(3), 177-201.

Te Kura Māori. (2010). Exploring kura engagement strategies with whānau, Iwi and kura in regards to

Marautanga-ā-kura: A research project for The Ministry of Education. Wellington: Victoria University.

Trahar, S. (2009). Beyond the story itself: Narrative inquiry and autoethnography in intercultural research in higher education. Forum: Qualitative Social Research, 10(1), Art. 30. 